\title{
Proposal for a composite structure and graphic design for a parking barrier
}

\author{
Liana Hancu, ${ }^{1, *}$, Gabriel Marc ${ }^{1}$, Adrian Popescu ${ }^{1}$, Paul Bere ${ }^{1}$ and Simona Rodean \\ ${ }^{1}$ Technical University of Cluj-Napoca, Manufacturing Engineering Department, ROMANIA
}

\begin{abstract}
In the paper there is presented a case study of a cabinet barrier for a car parking. The materials used for manufacture are changed with polymeric composites. A design is proposed for the cabinet and a manufacturing technology is considered. The composite material is designed, realized and tested with tensile test ant three bending test and the results are presented.
\end{abstract}

\section{Introduction}

A composite is a material made from two or more components with very different physical or chemical properties. The new material obtained has different characteristics from the individual components which remain separate and distinct within the finished structure. The new material may be preferred because they are stronger, lighter, or less expensive when compared to traditional materials.

More recently, as presented in [1-3], researchers have also begun to actively include sensing, actuation, computation and communication into composites, which are known as Robotic Materials.

A composite material is made of the matrix, the reinforcement and the additives (coupling agents, catalysts and accelerators, pigments and fillers) [4-5].

Polymeric composites are combinations of two materials where the matrix is a polymeric material and the other one, called reinforcing phase, is in the form of fibers, sheets or particles and is embedded in the first one. Matrix materials are usually thermoplastics or thermosets like polyester, epoxy, silicon, phenolic, and so on. Fibers commonly used are: glass, graphite, boron and aramids.

The advantages such as light weight, low density, corrosion resistance, high stiffness, high heat resistance, fatigue resistance and high strength made them very attractive for industry.

There are many ways to arrange the reinforcement and the differences in the way the fibers are laid out give different characteristics to the material. Reinforcement usually makes the material more rigid and delays crack propagation. The fibers can greatly improve the composite's properties if they are properly select and arrange [6-11].

Fiber-reinforced composite materials are usually of two categories: short fiberreinforced materials and continuous fiber-reinforced materials. Continuous reinforced

\footnotetext{
${ }^{*}$ Corresponding author: Liana.Hancu@tcm.utcluj.ro
} 
materials are usually manufactured in layered or laminated structures which are available in a variety of forms.

Many researchers studied the mechanical behavior of a glass fiber reinforced composite and presented their connection with the fiber strength and modulus, fiber weight fraction, orientation, type, chemical stability, matrix strength and the interface bonding between the fiber and the matrix [12-18].

Considering that the strength and stiffness is not the same in all directions of a multilayered composite, the use of such a material needs a very accurate manufacture but only after the mechanical proprieties are determined.

\section{Case study considerations}

\subsection{Product}

A lot of products from the market, made of plastics are nowadays changed by similar ones but made of composites. The new technology that is needed is very different from the initial one. Such a product was a challenge for the authors who consider that the barrier cage used for automatic parking needs to be improved.

The proposal for the upper part of the product is presented in figure 1. The SolidWorks 2016 program was used to build the 3D model.

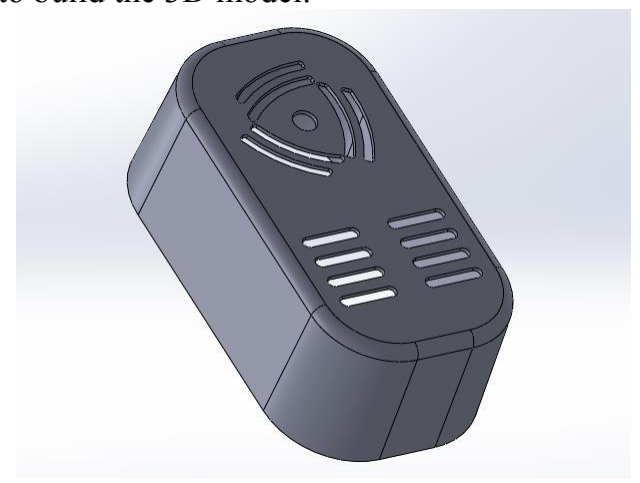

Fig. 1. Upper part of the barrier cabinet.

The barrier cabinet is designed to replace the old models currently available on the market. The upper part of the cabinet will be made by resin transfer moulding, and the material used for the reinforcement is a bidirectional glass fiber fabric. The dimensions of the upper part of the barrier are as follows: $1000 \times 550 \times 350 \mathrm{~mm}$.

\subsection{Manufacturing}

The manufacturing technology proposed for the part is Resin Transfer Moulding (RTM) which is a low pressure moulding process in a closed mould for moderate volume production quantities.

Metered mixing equipment is used to control resin and catalyst quantities that are mixed through a mixer and injected into the mould port.

The main advantages that make the technology proper for our product are a uniform thickness, good quality surface for both sides of the component and low emissions. For optimum surface finish, a gel coat would be applied to the mould surface prior to moulding. 


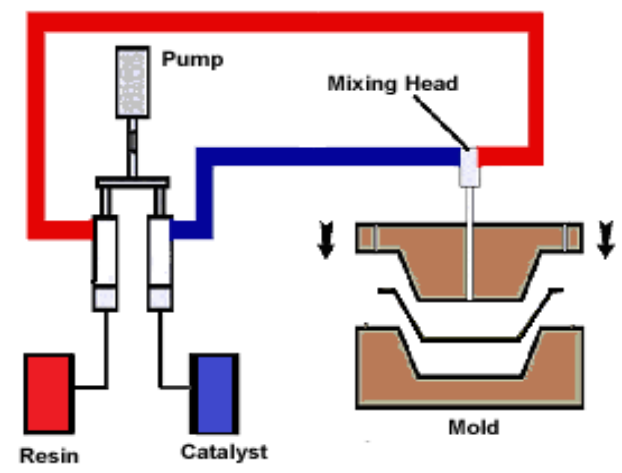

Fig. 2. Resin transfer moulding.

Fabrics or mats are usually used and laid upon the bottom (female) part of the mould. Preformed glass reinforcements are often used for complex mould shapes. The upper mould tool is then clamped over the first, and the resin is injected into the cavity. The technology is in some cases improved with the usage of vacuum which is applied to the mould cavity to assist resin into the fabrics. This is known as Vacuum Assisted Resin Injection (VARI). After all the fabric is wet out, the laminate is allowed to cure at ambient or elevated temperature.

\subsection{Samples}

Experimental research was performed in order to determine the mechanical characteristics for the proposed structure of the barrier upper part in order to be strength and also flexible as the usually demands for such a product are. The necessary experiments are tensile test and three point bending test.

In order to obtain the samples, a plate with initial dimensions of $250 \times 250 \times 2 \mathrm{~mm}$ was obtained using Resin transfer moulding technology.

An epoxy resin, type Epiphen RE 4020 / DE 4020, was used for the matrix. The mixing ratio of the parts (in weight) is 100:30, according to the manufacturer recommendations.

For reinforcement 4 layers of bidirectional balanced glass fabric by $300 \mathrm{~g} / \mathrm{m}^{2}$ was used and the calculated fiber volume fraction is $62.5 \%$, which is very close to the maximum value of $65 \%$ that can be realized with this technology. The whole composite system was cured at $20^{\circ} \mathrm{C}$ for 24 hours.

From the plate obtained in this way, six samples for both tensile test and for three point bending test were cut.

The samples dimensions are made according to the prescriptions from the standards EN ISO 527-4 and ISO 527-5-2000 for tensile test and ISO 1425:2013 for bending tests.

The cutting of the samples was made with the water cutting machine.

\section{Experimental results}

The samples were tested on a Zwick/Roel Materials testing machine Z150 with test Control $\mathrm{PC}$ and the software testXpert II was used.

The results from the tensile tests are presented in figure 3 and the values registered by the machine are presented in table 1. It can be seen that all the graphics from sample 1 to 6 have the same slope, almost linear and this means that the plate was manufactured properly. The deformation is almost linear till the maximum force, when the specimens breaks, and is recorded the maximum force and deformation. 
The medium value for the 6 samples, " $x$ ", the dispersion of the results, "s" and the dispersal coefficient, " $v$ ", are calculated by the machine software and presented in table 2. They all indicate that the manufacturing through Resin Transfer Moulding offers good characteristics all over the surface and this is very important for a part that is supposed to be hit during usage.

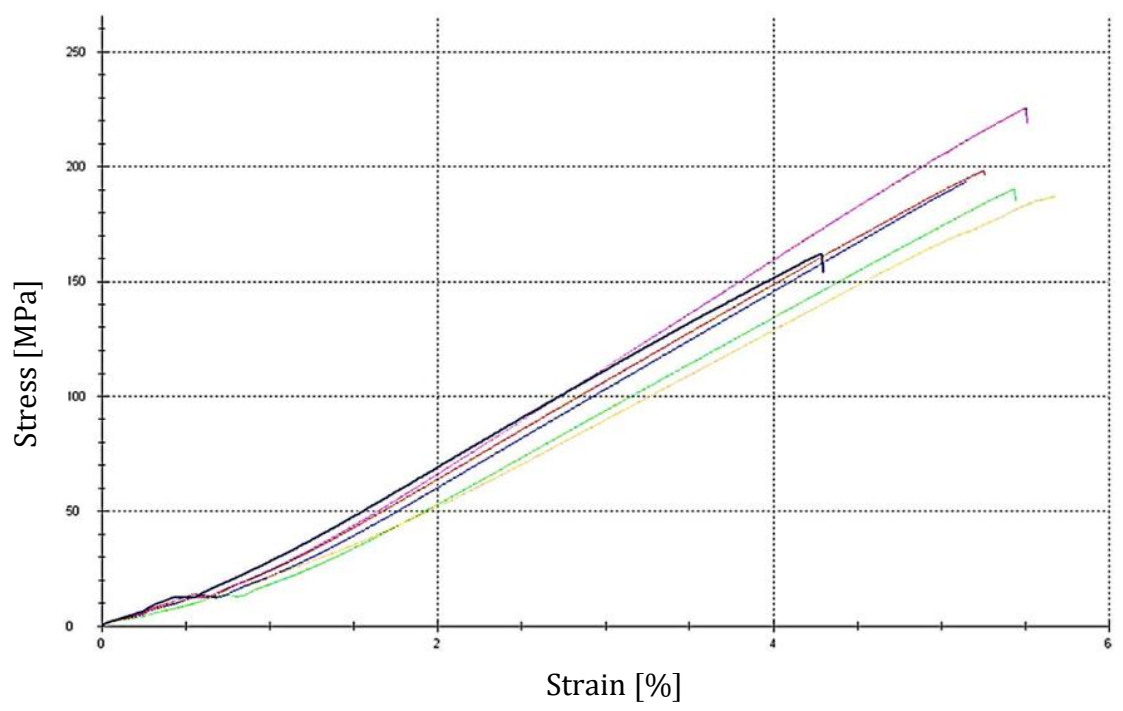

Fig. 3. Results of tensile tests.

Table 1. Individual values for the samples.

\begin{tabular}{|c|c|c|c|c|c|c|c|c|c|c|c|c|c|c|c|c|}
\hline $\mathrm{Nr}$ & Date & $\begin{array}{c}\sigma_{\text {low }} \\
\mathrm{MPa}\end{array}$ & $\begin{array}{l}\text { Ohigh } \\
\mathrm{MPa}\end{array}$ & $\begin{array}{c}\mathrm{Et} \\
\mathrm{MPa}\end{array}$ & $\begin{array}{l}\sigma_{x 1} \\
\mathrm{MPa}\end{array}$ & $\begin{array}{c}\sigma_{\mathrm{r}} \\
\mathrm{MPa}\end{array}$ & $\begin{array}{l}\varepsilon_{\gamma} \\
\%\end{array}$ & $\begin{array}{c}\sigma_{\mathrm{M}} \\
\mathrm{MPa}\end{array}$ & $\begin{array}{l}\varepsilon_{M} \\
\%\end{array}$ & $\begin{array}{l}\varepsilon_{\mathrm{tM}} \\
\%\end{array}$ & $\begin{array}{c}\sigma_{\theta} \\
\mathrm{MPa}\end{array}$ & $\begin{array}{l}\varepsilon_{\theta} \\
\%\end{array}$ & $\begin{array}{l}\varepsilon_{\theta} \\
\%\end{array}$ & $\begin{array}{c}\mathrm{b} \\
\mathrm{mm}\end{array}$ & $\begin{array}{c}\mathrm{h} \\
\mathrm{mm}\end{array}$ & $\begin{array}{c}\mathrm{AD}_{0} \\
\mathrm{~mm}^{2}\end{array}$ \\
\hline 2 & $6 / 6 / 2017$ & 1.727 & 5.952 & 2080 & - & - & - & 198 & 5.3 & 5.3 & 198 & 5.3 & 5.3 & 25 & 2 & 50.00 \\
\hline 3 & $6 / 6 / 2017$ & 1.521 & 4.348 & 1400 & - & - & - & 190 & 5.4 & 5.4 & 190 & 5.4 & 5.4 & 25 & 2 & 50.00 \\
\hline 4 & $6 / 6 / 2017$ & 1.670 & 5.309 & 1830 & - & - & - & 193 & 5.1 & 5.1 & 193 & 5.1 & 5.1 & 25 & 2 & 50.00 \\
\hline 5 & $6 / 6 / 2017$ & 1.563 & 5.584 & 2020 & - & - & - & 187 & 5.7 & 5.7 & 187 & 5.7 & 5.7 & 25 & 2 & 50.00 \\
\hline 6 & $6 / 6 / 2017$ & 1.960 & 5.947 & 1980 & - & - & - & 225 & 5.5 & 5.5 & 225 & 5.5 & 5.5 & 25 & 2 & 50.00 \\
\hline 7 & $6 / 6 / 2017$ & 1.933 & 6.710 & 2390 & - & - & - & 162 & 4.3 & 4.3 & 162 & 4.3 & 4.3 & 25 & 2 & 50.00 \\
\hline
\end{tabular}

Table 2. Medium values for the series of 6 samples.

\begin{tabular}{c|c|c|c|c|c|c|c|c|c|c|c|c|c|c|c} 
Series & $\sigma_{\text {low }}$ & $\sigma_{\text {high }}$ & $E_{t}$ & $\sigma_{x 1}$ & $\sigma_{Y}$ & $\varepsilon_{Y}$ & $\sigma_{M}$ & $\varepsilon_{M}$ & $\varepsilon_{t M}$ & $\sigma_{\theta}$ & $\varepsilon_{\theta}$ & $\varepsilon_{t \theta}$ & $b$ & $h$ & $A_{0}$ \\
$n=6$ & $\mathrm{MPa}$ & $\mathrm{MPa}$ & $\mathrm{MPa}$ & $\mathrm{MPa}$ & $\mathrm{MPa}$ & $\%$ & $\mathrm{MPa}$ & $\%$ & $\%$ & $\mathrm{MPa}$ & $\%$ & $\%$ & $\mathrm{~mm}$ & $\begin{array}{c}\mathrm{mm} \\
\mathrm{mm}^{2}\end{array}$ \\
\hline $\bar{x}$ & 1.729 & 5.642 & 1950 & - & - & - & 193 & 5.2 & 5.2 & 193 & 5.2 & 5.2 & 25 & 2 & 50.00 \\
\hline$s$ & 0.184 & 0.790 & 328 & - & - & - & 20.4 & 0.49 & 0.49 & 20.4 & 0.49 & 0.49 & 0.000 & 0.000 & 0.00 \\
\hline$\nu$ & 10.64 & 14.00 & 16.83 & - & - & - & 10.58 & 9.44 & 9.44 & 10.58 & 9.44 & 9.44 & 0.00 & 0.00 & 0.00
\end{tabular}

The results from the bending tests are presented in figure 4 and the values registered by the machine are presented in table 3. It can be seen that all the graphics from sample 1 to 6 have the same shape and this means that the material has the same characteristics all over the plate.

The medium value for the 6 samples, " $x$ ", the dispersion of the results, "s" and the dispersal coefficient, " $v$ ", are calculated by the machine software and presented in table 4 . They all indicate that the manufacturing through Resin Transfer Moulding offers good characteristics all over the surface and this is very important for a part that is supposed to be hit during usage. 


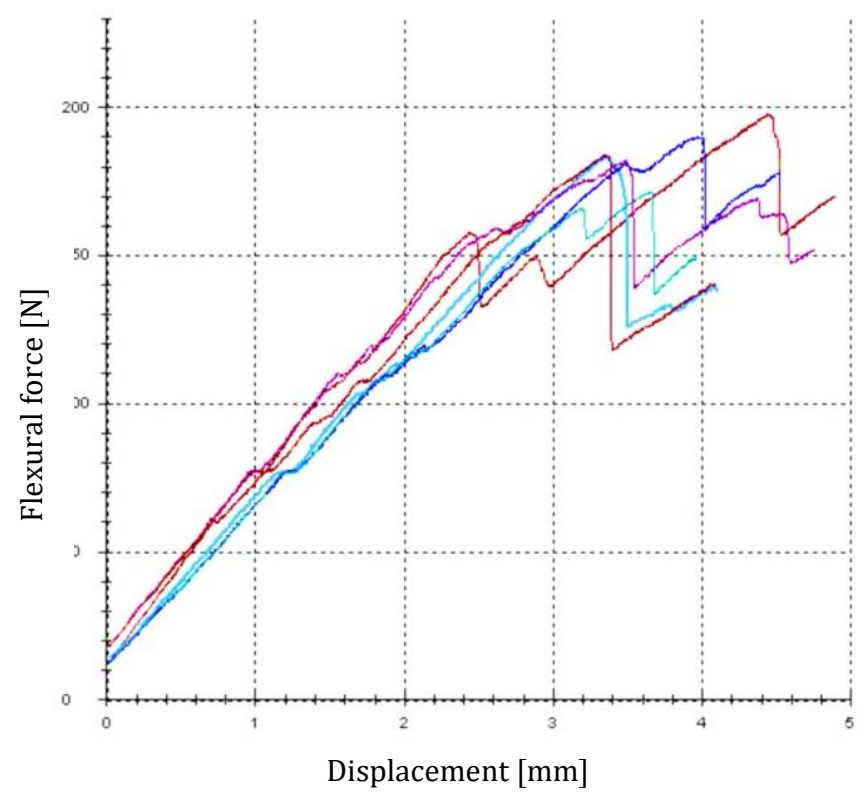

Fig. 4. Results of three points bending test.

Table 3. Individual values for the samples.

\begin{tabular}{c|c|c|c}
$\mathrm{Nr}$ & $\begin{array}{c}\text { Height } \\
\mathrm{mm}\end{array}$ & $\begin{array}{c}\text { Diameter d0 } \\
\mathrm{mm}\end{array}$ & $\begin{array}{c}\text { Fmax. } \\
\text { kN }\end{array}$ \\
\hline 106 & 272.43 & 20 & 0.20 \\
\hline 108 & 272.47 & 20 & 0.18 \\
\hline 109 & 272.63 & 20 & 0.19 \\
\hline 110 & 272.70 & 20 & 0.17 \\
\hline 111 & 272.61 & 20 & 0.18 \\
\hline 112 & 272.62 & 20 & 0.18
\end{tabular}

Table 4. Medium values for the series of 6 samples.

\begin{tabular}{c|r|c|c}
$\begin{array}{c}\text { Series } \\
\mathrm{n}=6\end{array}$ & $\begin{array}{c}\text { Height } \\
\mathrm{mm}\end{array}$ & $\begin{array}{c}\text { Diameter d0 } \\
\mathrm{mm}\end{array}$ & $\begin{array}{c}\text { Fmax. } \\
\mathrm{kN}\end{array}$ \\
\hline$\overline{\mathrm{x}}$ & 272.58 & 20 & 0.18 \\
\hline $\mathrm{s}$ & 0.10 & 0.000 & 0.01 \\
\hline $\mathrm{v}$ & 0.04 & 0.00 & 4.72
\end{tabular}

Before starting the test, the machine is set to the test parameters. As seen in figure 4 , the behavior of the composite has four stages during the test. The first stage, almost linear, explains the elastic deformation of the composite. The second stage begins after the load reaches a peak value, when diminish of about $20-50 \%$ of the peak load was observed in composite laminate structures.

This load diminish appears because of the fiber cracking and delamination, or some defects in the structure of the composite. In the third stage, because only the reinforcement carried the load, the specimen grew again but never exceeded the previous peak load. 


\section{Conclusions}

The case study presented shows that using a polymeric based composite material the product is more resistant to pressure than plastics without reinforcement. The technology proposed has the advantage, compared to other technologies used for composite parts, that assures a good quality for the part both in geometry and in quality surface. The design of the composite structure is important for obtaining high strength and also good flexural proprieties. The composite material was realized and tested and the results show a good behavior at traction but some delamination at bending.

The appearance and propagation of delamination between layers is of great importance and the prediction of the failure of the composite structures should be considered for study. One possible causes of delamination in our case can be the uniform structure used for the part as all the layers were in the same direction and the penetration of the resin between them was, in this way, difficult.

This work was supported by a grant of the Romanian National Authority for Scientific Research and Innovation, CNCS/CCCDI-UEFISCDI, project number PN-III-P2-2.1-96BG-2016-0210, within PNCDI III.

\section{References}

1. M.A. McEvoy and N. Correll. Materials that couple sensing, actuation, computation, and communication. Science 347(6228) (2015)

2. T. Sathishkumar, S. Satheeshkumar, J. Naveen, J. Reinf. Plast. compos. 33, 1258-1275 (2014)

3. J.M. Stickel, M. Nagarajan, Int. J. Appl. Glass Sci., 3122-3136 (2012)

4. C. Florea, H. Iancau, A. Popescu, M. Simon, P. Bere, COMAT (2010)

5. A. Azzam and W.Li,, IOP Conf. Ser. Mater. Sci. Eng. 6, 2012016, Global Conference on Polymer and Composite Materials (2014)

6. G. L. Enachescu, M. F. Stefanescu, J Plastic Mater 53, 198-201 (2016).

7. G.M. Krolczyk., P. Nieslony, J.B. Krolczyk, I. Samardzic, S. Legutko, S. Hloch, S. Barrans, R.W. Maruda, J. Measurement 7, 2003-2013 (2015)

8. R. Udroiu, A. Nedelcu, B. Deaky, Environmental Engineering and Management Journal 10(9), 1387-1394 (2011)

9. W. Plowucha and W. Jakubiec, Quality and Innovation in Engineering and Management 183-186 (2011)

10. P. Bere, C. Neamtu, Central European Journal of Engineering, 1-7 (2014)

11. I. Campbell, et al., Rapid Prototyping Journal, 14(5), 271-279 (2008)

12. B. Liu, R.I. Campbell, and E. Pei, Real-time integration of prototypes in the product development process. Assembly Automation, 33(1), 22-28 (2013)

13. M.F. Ştefănescu, Mat. Plast. 35(4), 231-238 (1998)

14. M.F. Ştefănescu, Mat. Plast. 43(3), 254-257 (2006)

15. J.B. Krolczyk, Transactions of FAMENA, 37(4), 43-54 (2014)

16. G. Krolczyk, J.B. Krolczyk, S. Legutko, A. Hunjet, Tehnički vjesnik/Technical Gazette, 21(2), 447-450 (2014)

17. I.A. Popan, N. Balc, A.I. Popan, MSE, MATEC Web Conf., 121 (2017)

18. M. Shirinbayan, J. Fitoussi, M. Bocquet, F. Meraghni, B. Surowiec, A. Tcharkhtchi, Composites Part.B. Engineering, 115(15), 3-13 (2017) 